\title{
The Investigation of the Effects of the Very and Mild Preterm Birth on the Musculoskeletal System
}

\author{
(1) Hayriye Kul Karaali,, (1D Sema Savcı, ${ }^{2}$ (1) Ayşe Özden, ${ }^{3}$ (D) Celal Gençoğlu, ${ }^{4}$ () Nuray Duman ${ }^{5}$ \\ 'Department of Physiotherapy and Rehabilitation, Manisa Celal Bayar University, Faculty of Health Sciences, \\ Manisa,Turkey \\ ${ }^{2}$ Faculty of Physical Therapy and Rehabilitation, Dokuz Eylul University, Izmir, Turkey \\ ${ }^{3}$ Department of Physical Therapy and Rehabilitation, Faculty of Health Sciences, Izmir Tınaztepe University, \\ Izmir, Turkey \\ ${ }^{4}$ Department of Sport Sciences Physical Education and Sports Teaching, Dokuz Eylul University Faculty of Sport \\ Sciences, Dokuz Eylul University, Izmir, Turkey \\ ${ }^{5}$ Department of Pediatrics, Dokuz Eylul University, Faculty of Medicine, Izmir, Turkey
}

Please cite this article as: Kul Karaali H, Savcı S, Özden A, Gençoğlu C, Duman N. The Investigation of the Effects of the Very and Mild Preterm Birth on the Musculoskeletal System. Anatol J Family Med 2020;3(3):205-210.

Address for correspondence: Dr. Hayriye Kul Karaali. Department of Physiotherapy and Rehabilitation, Manisa Celal Bayar University, Faculty of Health Sciences, Manisa,Turkey Phone: +90 5327607525

E-mail: hayriyeklkrl@gmail.com

Received Date: 29.08.2019

Accepted Date: 12.05 .2020

Published online: 07.12 .2020

@Copyright 2020 by Anatolian Journal of Family Medicine Available online at www.anatoljfm.org

OPEN ACCESS

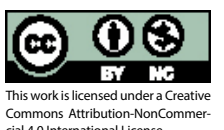

\section{ABSTRACT}

Objectives: The aim of study was to examine the musculoskeletal system of the very preterm (VP) and mild preterm (MP) born children and to compare them with their term born peers.

Methods: Children born with VP and MP between January 1998 and April 2003, whose contact information was available from patient records, were included in our study. The control group consisted of volunteers who were admitted to the Department of Child Health and Diseases during the study. Skeletal muscle mass, fat free mass, posture and physical fitness of all participants were assessed.

Results: Eighteen (28.2\%) VP, 23 (35.9\%) MP and 23 (35.9\%) term born children were included in this study. Total posture score was 6.0 [3.5] in the VP group, 5.0 [5.0] in the MP group and 4.0 [2.0] in the term group and the difference between VP and term group was significant $(p=0.004)$. Munich Physical Fitness Test score was $44.0 \pm 6.3$ in the VP group, $45.6 \pm 4.8$ in the MP group and 51.9 \pm 3.8 in the term group and the difference between VP and term groups and between MP and term groups was significant ( $p=0.001$ and $p=0.001$, respectively).

Conclusion: The musculoskeletal system of the VP and MP born school age children is affected negatively in comparison to their term peers. This situation suggests that very and MP born children later on may have potential health problems originated from musculoskeletal system.

Keywords: Musculoskeletal system, preterm birth, posture, physical fitness

\section{INTRODUCTION}

In recent years, there has been an increased interest towards preterm born children without a neuro-developmental problem, and it has been tried to obtain data related to physical activity levels, pulmonary function and exercise capacity which could be risk factors for chronic diseases especially in the future. ${ }^{[1-3]}$ In most of these studies, although in terms of physical activity levels, pulmonary functions and exercise capacity, the preterm born children lag behind the term peers, studies evaluating the musculoskeletal system that are known to be associated with these parameters are only available in a limited number in the literature. In 
addition, the majority of these studies include data about severely preterm born children. ${ }^{[4-5]}$ Therefore, the present study aimed to evaluate the musculoskeletal system of the very and mild preterm born children and to compare them with their term born peers.

\section{METHOD}

This study performed at the Dokuz Eylul University Faculty of Medicine Hospital (FMH) in the Neonatal Unit of the Department of Child Health and Diseases, the patient records were evaluated and the patients who were born between the dates January 1998 and April 2003, were 8-12 years old during the study, whose contact information could be reached, and who volunteered to take part in the study, were included in the study. Twenty-two (5.0\%) of the patients had died. One $(0.2 \%)$ of the patients was diagnosed as having cancer in the subsequent years. Sixty-four $(14.4 \%)$ of the patients alive had neurological problems and $12(2.7 \%)$ of them had cardiac problems. The contact information could not be reached in $292(65.8 \%)$ of the patients. Among the 53 (11.9\%) patients with the contact information, while 12 (22.6\%) of them refused to participate in the research. Eighteen (28.2\%) the very preterm (VP) and $23(35.9 \%)$ mild preterm (MP) agreed to be enrolled in the research.

By taking the reached number of patients in to consideration, the number of patients in the control group was determined. The control group consisted of volunteers who were admitted to the Healthy Children Unit of the Dokuz Eylul University FMH Department of Child Health and Diseases during the study. Three groups of children were included in the study. The first group consisted of VP born children, the second group MP born children, and the third group healthy term born peers (According to gestational age at birth; VP: 28-31 weeks, MP: 32-36 weeks, Term: 3741 weeks). ${ }^{[6]}$ Term-born children were included in to the study after having been evaluated by a specialist doctor of pediatrics. Children's demographic and clinical information were recorded. In addition, the families of the children were asked whether the children were doing regular physical activity, and the answers were recorded. Skeletal muscle mass (SMM), fat free mass (FFM), posture and physical fitness assessments were made.

Skeletal Muscle Mass and Fat Free Mass: SMM and FFM were determined by the bioelectrical impedance analysis method. During measurements, InBody 720 (Biospace 3.0 Seoul, Korea) device was used. ${ }^{[7]}$

Posture: Observational posture analysis was performed using the form of Corbin et al. when people are in anatomical position, they are observed from lateral and posterior and posture states are scored ${ }^{[8]}$ Head tilt, excessive thoracic kyphosis, excessive lumbar lordosis, weakness of abdominal muscles, genu recurvatum, anterior balance and scoliosis symptoms (shoulder level and hip level inequalities, lateral curvature of the spine, gibbosity) are evaluated. Scoring is performed according to the severity of the observed postural disorders $(0=$ none, $1=$ mild, $2=$ moderate, $3=$ severe). The total posture score is calculated by summing the scores obtained from the lateral observation and the posterior observation. The increase in the total score indicates that the posture has worsened.

Physical Fitness: Munich Physical Fitness Test (MPFT) is a well known and popular test to assess some aspects of physical fitness in children and adolescents aged from six to eighteen years in schools. The MPFT is easy to use and has a clear protocol which makes it possible to convert performance to anormative standard. With the objective scores, based on age and gender, a peer comparison and an interpretation of the motor performance can be done. MPFT consists of six tasks (ball bouncing, sandbag throwing, bending, jumping, hanging and step climbing). ${ }^{[9]}$ MPFT score is determined by comparing the obtained data with the normal values determined according to age and gender. The higher the score, the higher the fitness level. The test manual can be downloaded from the website "http:// www.sportunterricht.de/mft/mft.pdf."[10]

Children with a history of metabolic or heart disease, rheumatic diseases, cerebral palsy, mental retardation, other major neurological problems, cancer, acute illness or infection (for at least six weeks), and children who were not cooperating or volunteering to participate were excluded in this study.

For the statistical evaluation of the data of the study, SPSS 17.0 statistical software program was used. Frequency, percentage, mean, standard deviation, median and interquartile range (IQR) were used as descriptive statistics. Analytical methods (Kolmogorov-Smirnov and Shapiro-Wilk tests) and histogram distribution were used to test normality by comparing our data with a normal distribution with the same mean and standard deviation as our sample. A chisquare test was used to examine the comparison of categorical data. When the data showed a normal distribution, One-Way ANOVA test was used to compare independent groups in the data obtained by continuous data. The variance homogeneity of the variables was evaluated by Levene test. For the post-hoc test selection, while Tamhane's T2 was used to compare the non-homogeneous variables, it was analyzed by Bonferroni test regarding variance homogeneity. For the data without normal distribution, the Kruskal-Wallis $\mathrm{H}$ test was used. Afterwards, Bonferroni 
correction was used for post-hoc analysis in meaningful groups. Results were considered statistically significant at $\mathrm{p}<0.05$.

\section{RESULTS}

During the study, a total of 444 patient records were obtained who were born between 28-36 gestational weeks. Eighteen (28.2\%) VP, 23 (35.9\%) MP and 23 (35.9\%) termborn children were included in this study. Eleven (61.1\%) of children were male in the VP group, $14(60.9 \%)$ of children were male in the MP group and 14 (60.9\%) of children were male in the term group. Physical and clinical characteristics of the children are summarized in Table 1.

In the postnatal period, 1 (5.6\%) of the VP born was diag- nosed as having grade-1 Bronchopulmonary Dysplasia. Two (11.1\%) of the VP born patients and $3(13.0 \%)$ of the MP born patients had a history of maternal smoking. Eight (44.4\%) patients in the VP group, 17 (73.9\%) in the MP group, and 13 (56.5\%) in the term group were observed to perform activities such as cycling, walking, football, basketball, volleyball, tennis, swimming, karate, gym and folk dances regularly $(p=0.150)$. Comparison of FFM and SMM between groups are shown in Table 2. Total posture score was 6.0 [3.5] in the VP group, 5.0 [5.0] in the MP group and 4.0 [2.0] in the term group and the difference between VP and term group is significant $(p=0.004)$. Comparison of posture analysis score between groups is shown in Table 3. MPFT score was $44.0 \pm 6.3$ in the VP group, $45.6 \pm 4.8$ in the

\section{Table 1. Physical and clinical characteristics of the children}

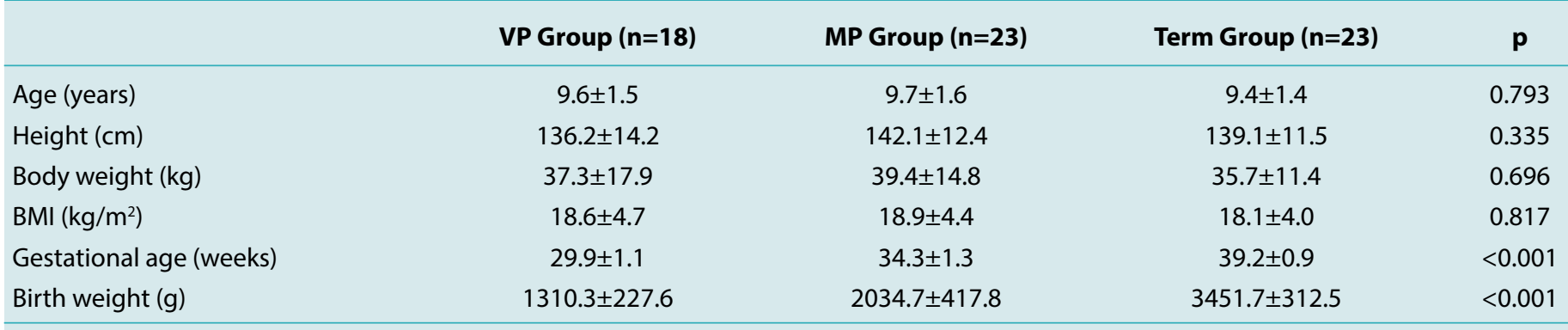

BMI: Body mass index; MP: Mild preterm; VP: Very preterm

Values are expressed as mean \pm SD.

One-Way ANOVA Test. Between all groups post-hoc tests (Bonferroni).

Table 2. Comparison of fat free mass and skeletal muscle mass between groups

\begin{tabular}{|c|c|c|c|c|}
\hline & VP Group ( $n=18)$ & MP Group ( $n=23)$ & Term Group $(n=23)$ & $\mathbf{p}$ \\
\hline Skeletal muscle mass $(\mathrm{kg})$ & $11.9[7.5]$ & $13.8[6.2]$ & $14.1[6.3]$ & 0.530 \\
\hline
\end{tabular}

MP: Mild preterm; VP: Very preterm.

Values are expressed as median[IQR].

Kruskal-Wallis H Test.

Table 3. Comparison of posture analysis score between groups

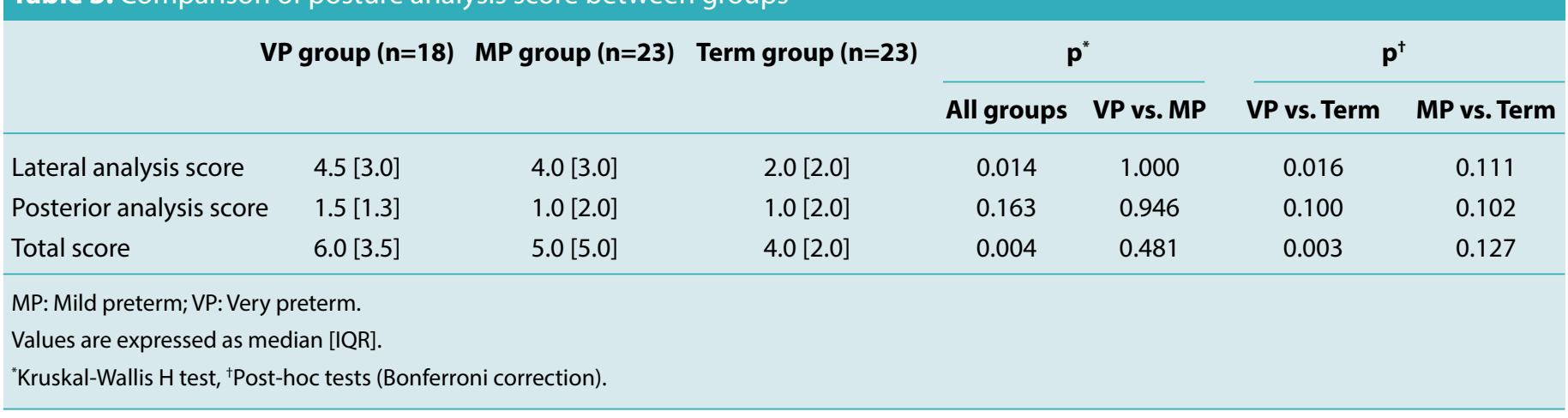


MP group and $51.9 \pm 3.8$ in the term group. The difference between VP and term groups and between MP and term groups is significant ( $p=0.001$ and $p=0.001$, respectively). MPFT scores of three groups is shown in Table 4.

\section{DISCUSSION}

Based on the main results obtained from our study, it was found that VP and MP born children had a lower physical fitness than the term peers and VP born children were found to have more postural disturbances than their term peers.

Skeletal Muscle Mass and Fat Free Mass: In most of the studies in the literature, severely preterm born children and/or preterm born children with a very low birth weight have been studied in terms of their growth during childhood and adulthood period, their body mass index, body fat weight and presence of obesity. ${ }^{[11-15]}$ As well, there are also studies reporting a correlation between birth weight and lean body weight in later stages of life. Therefore, it is worth elaborating more about studies which classify the preterm born children and compare them afterwards with their term peers. ${ }^{[16-20]}$

There was a study that measured limb muscle area in preterm born children. In that study, limb muscle area of 102 newborn with the mean chronological age of 28.5 days were measured by ultrasound. Among newborns that were classified according to the gestational weeks as 23-28 weeks, 29-32 weeks, 33-36 weeks and 37-42 weeks, preterm born infants who were born between the 33-36 gestation weeks were found to have the lowest muscle area $\left(5.4 \mathrm{~cm}^{2}\right.$, $4.8 \mathrm{~cm}^{2}, 2.7 \mathrm{~cm}^{2}, 6.6 \mathrm{~cm}^{2}$, respectively). ${ }^{[21]}$ The muscle area measurement was not done in this study, but SMM was measured, and contrary to the aim of this study, although not statistically significant, it was found that MP group with a gestation age of 32-36 weeks had the maximum muscle mass.

Posture: There is no any study in the literature examining the postural status of school-age children or young adults with a history of preterm birth. Therefore, this study may contribute to the literature, since it includes data on postural status of preterm children.

The postural alignment of VP group is significantly impaired with respect to term control group. In this study, the flexibility and muscle endurance evaluated in terms of physical fitness was significantly decreased in the VP group with respect to the term group, and this may have caused

Table 4. Comparison of Munich Physical Fitness Test scores of three groups

VP group $(n=18)$ MP group $(n=23)$ Term group $(n=23)$

p

All groups VP vs. MP VP vs. Term MP vs. Term

\begin{tabular}{|c|c|c|c|c|c|c|c|}
\hline Ball bouncing (times) & $37.5 \pm 10.5$ & $41.5 \pm 11.5$ & $41.7 \pm 11.1$ & $0.420^{*}$ & $0.776^{\ddagger}$ & $0.702^{\ddagger}$ & $1.000^{\ddagger}$ \\
\hline Ball bouncing score & $53.2 \pm 16.0$ & $56.4 \pm 10.9$ & $57.8 \pm 10.5$ & $0.496^{*}$ & $1.000^{\ddagger}$ & $0.731^{\ddagger}$ & $1.000^{\ddagger}$ \\
\hline Sandbag throwing (total) & $3.0[7.3]$ & $5.0[7.0]$ & $8.0[7.0]$ & $0.036^{\dagger}$ & $1.000^{\S}$ & $0.037^{\S}$ & $0.258^{\S}$ \\
\hline Bending $(\mathrm{cm})$ & $-10.5[11.0]$ & $-9.0[11.0]$ & $2.0[9.0]$ & $<0.001^{\dagger}$ & $1.000^{\S}$ & $0.001^{\S}$ & $0.003^{\S}$ \\
\hline Bending score & $36.9 \pm 8.5$ & $37.8 \pm 8.7$ & $48.3 \pm 9.9$ & $<0.001^{*}$ & $1.000^{\ddagger}$ & $0.001^{\neq}$ & $0.001^{\ddagger}$ \\
\hline Hanging (sec) & $6.8[12.0]$ & $5.8[6.0]$ & $15.0[15.0]$ & $<0.001^{\dagger}$ & $1.000^{\S}$ & $0.007^{\S}$ & $0.001^{\S}$ \\
\hline Hanging score & $41.3 \pm 15.1$ & $43.5 \pm 7.8$ & $55.1 \pm 8.7$ & $<0.001^{*}$ & $1.000^{\ddagger}$ & $<0.001^{\ddagger}$ & $0.001^{\ddagger}$ \\
\hline $\begin{array}{l}\text { Step climbing heart rate } \\
\text { difference (beat/min) }\end{array}$ & $5.5[7.8]$ & $6.0[11.0]$ & $1.0[11.0]$ & $0.039^{+}$ & $1.000^{\S}$ & $0.352^{\S}$ & $0.036^{\S}$ \\
\hline
\end{tabular}

MP: Mild preterm; MPFT; Munich physical fitness test; VP:Very preterm.

Values were expressed as mean \pm SD and median [IQR].

"One-Way ANOVA Test, and 'Kruskal-Wallis $\mathrm{H}$ test.

${ }^{\ddagger}$ After One-Way ANOVA, selection of post-hoc testswas made according to Levene's homogeneity test. If the variances were homogeneous Bonferroni, if not Tamhane's $T 2$ was used.

${ }^{5}$ After Kruskal-Wallis $\mathrm{H}$ test, Bonferroni correction was used for post-hoc analysis. 
postural disorders more to be seen in the VP group. Taking the data obtained into consideration, in the adulthood of VP born children, the incidence of having low back and neck pain may be more than their term peers. Therefore, it would be useful to organize postural alignment training and individual workout programs for the VP born children.

Physical Fitness: Physical fitness is a concept related to health in general. A higher physical fitness is closely associated with optimal growth and development, reduction of musculoskeletal problems, ensuring optimal posture, reducing the risk of having chronic diseases such as coronary heart disease, hypertension and diabetes. ${ }^{[8,22,23]}$ In the literature, regarding the studies evaluating the physical fitness of preterm infants who face with health problems since the beginning of life, and who are more at risk of having a chronic disease at an advanced age, Rogers's and Svien's work is remarkable. Rogers et al. showed that the anaerobic power which was evaluated by vertical jump, the muscle endurance which was evaluated by push-ups and partial curl-ups, and the flexibility which was evaluated by bending forward and popliteal angle measurement, decreased significantly in preterm born children with respect to the term peers. ${ }^{[24]}$ Similarly, Svien demonstrated that the flexibility which was evaluated by sit-and-reach test and joint laxity (the wrist joint, knee joint, the first and fifth metacarpophalangeal joint) and muscle strength and endurance which were evaluated by using the BruininksOseretsky Test of Motor Proficiency test battery, decreased significantly in the preterm born children with respect to the term peers. ${ }^{[25]}$

Unlike the above mentioned studies, MPFT was used in our study. MPFT which is used in physical fitness evaluation of healthy and sick children, is a distinctive test by which the data obtained from the measurement can be compared with normal values as determined by age and sex. ${ }^{[2,26]}$ Similar to the above mentioned studies, the physical fitness of both the VP and the MP born school age children were found to be decreased with respect to their term peers in this study. When the subscores of the MPFT were evaluated, it was seen that especially flexibility (bending), strength and coordination (sandbag throwing), endurance and strength (hanging) parameters were affected more significantly. Flexibility is an important part of physical fitness. In our study, among the three groups, even though there was no difference in terms of age, gender, body weight, or body mass index, the flexibility was affected suggesting that flexibility might be affected due to internal factors affecting the muscle flexibility. New researchs on muscle flexibility, involving a larger number of preterm born subjects, could make the issue more lucid.
Despite the fact that the children included in the study had a similar physical activity habits, and that there was not a significant difference between the groups in terms of SMM, they still got lower scores in the sandbag throwing and hanging tests, suggesting that muscle endurance was affected earlier than the muscle strength. This result suggests that preterm born children may have trouble in sustaining daily life activities and we need new studies evaluating muscle endurance and muscle morphology.

Our study had some limitations. Firstly, the sample of the study was selected from the patients registered in our unit for easy access. Therefore, our results were limited to the findings obtained from our unit. Secondly, although dualenergy X-ray absorptiometry was a highly sensitive method for determining body composition, in our study the bioelectrical impedance analysis was used to measure SMM and FFM for its ease of application, even though it was a less reliable method.

\section{CONCLUSION}

The deterioration in postural alignment of VP born children is greater than that of term born peers. In addition, the physical fitness of VP and MP born children is worse than that of term born peers. This study suggests that postural alignment and physical fitness should be evaluated from the school age onwards to preserve the musculoskeletal health of preterm born children. And may be lays the foundation for the preparation of preventive approaches and/ or individual specific exercise program since childhood.

\section{Disclosures}

Peer-review: Externally peer-reviewed.

Conflict of Interest: None declared.

Ethics Committee Approval: The approval for the research was obtained from Dokuz Eylul University Non-invasive Researchs (Approval date: 13 Jan 2011, Approval number: 2011/01-10).

Authorship Contributions: Concept - H.K.K., S.S., N.D., A.O., C.G.; Design - H.K.K., S.S., N.D., A.O., C.G.; Supervision - H.K.K.; Materials - H.K.K., A.O., C.G.; Data collection \&/or processing - H.K.K., A.O., C.G.; Analysis and/or interpretation - H.K.K., S.S.; Literature search - H.K.K., S.S., N.D.; Writing - H.K.K., S.S.; Critical review - H.K.K., S.S., N.D., A.O., C.G.

\section{REFERENCES}

1. Doyle LW, Anderson PJ. Adult outcome of extremely preterm infants. Pediatrics 2010;126(2):34251. [CrossRef]

2. Gäddlin PO. Follow-up studies of very low birthweight children in Sweden. Acta Paediatr 2011;100(7):94049. [CrossRef]

3. Gibson AM, Doyle LW. Respiratory outcomes for the tiniest or most immature in-fants. Semin Fetal Neonatal Med 
2014;19(2):10511. [CrossRef]

4. Kajantie E, Strang-Karlsson S, Hovi P, Räikkönen K, Pesonen AK, Heinonen $\mathrm{K}$, et al. Adults born at very low birth weight exercise less than their peers born at term. J Pediatr 2010;157(4):61016.

5. Vrijlandt EJ, Gerritsen J, Boezen HM, Grevink RG, Duivermen AJ. Lung function and exercise capacity in young adults born prematurely. Am J Respir Crit Care Med 2006;173(8):8906. [CrossRef]

6. Moutquin JM. Classification and heterogeneity of preterm birth. BJOG 2003;110(20):303. [CrossRef]

7. Lim JS, Hwang JS, Lee JA, Kim DH, Park KD, Jeong JS, et al. Cross-calibration of mul-ti-frequency bioelectrical impedance analysis with eight-point tactile electrodes and dual-energy X-ray absorptiometry for assessment of body composition in healthy children aged 6-18 years. Pediatr Int 2009;51(2):2638.

8. Corbin CB. Concepts of fitness and wellness. Boston: McGrawHill; 2004.

9. Gruber W, Orenstein DM, Braumann KM, Hu G. Health-Related Fitness and Traina-bility in Children With Cystic Fibrosis. Pediatric Pulmonology 2008;43(10):95364. [CrossRef]

10. Munich Physical Fitness Test Manual. (transferred on April 5, 2010). Available from: URL: http://www.sportunterricht.de/ mft/mft.pdf. Assessed November 10, 2020.

11. Bracewell MA, Hennessy EM, Wolke D, Marlow N. The EPICure study: growth and blood pressure at 6 years of age following extremely preterm birth. Arch Dis Child Fetal Neonatal Ed 2008;93(2):10814. [CrossRef]

12. Chan GM, Armstrong C, Moyer-Mileur L, Hoff C. Growth and bone mineralization in children born prematurely. J Perinatol 2008;28(9):61923. [CrossRef]

13. Doyle LW, Faber B, Callanan C, Ford GW, Davis NM. Extremely low birth weight and body size in early adulthood. Arch Dis Child 2004;89(4):34750. [CrossRef]

14. Hack M, Schluchter M, Andreias L, Margevicius S, Taylor HG, Drotar D, et al. Change in prevalence of chronic conditions between childhood and adolescence among ex-tremely lowbirth-weight children. JAMA 2011;306(4):394401. [CrossRef]

15. Hack M, Schluchter M, Cartar L, Rahman M, Cutter L, Borawski E. Growth of very low birth weight infants to age 20 years. Pediatrics 2003;112(1):308. [CrossRef]

16. Euser AM, Finken MJ, Keijzer-Veen MG, Hille ET, Wit JM, Dekker FW. Dutch POPS-9 Collaborative Study Group. Associations between prenatal and infancy weight gain and BMI, fat mass, and fat distribution in young adulthood: a prospective cohort study in males and females born very preterm. Am J Clin Nutr 2005;81(2):4807. [CrossRef]

17. Murphy MJ, Metcalf BS, Jeffery AN, Voss LD, Wilkin TJ. Does lean rather than fat mass provide the link between birth weight, BMI, and metabolic risk?. Pediatr Dia-betes 2006;7(4):2114.

18. Sayer AA, Syddall HE, Dennison EM, Gilbody HJ, Duggleby SL, Cooper $\mathrm{C}$, et al. Birth weight, weight at $1 \mathrm{y}$ of age, and body composition in older men: findings from the Hertfordshire Cohort Study. Am J Clin Nutr 2004;80(1):199203. [CrossRef]

19. Singhal A, Wells J, Cole TJ, Fewtrell M, Lucas A. Programming of lean body mass: a link between birth weight, obesity, and cardiovascular disease?. Am J Clin Nutr 2003;77(3):72630.

20. Ylihärsilä H, Kajantie E, Osmond C, Forsén T, Barker DJ, Eriksson JG. Birth size, adult body composition and muscle strength in later life. Int J Obes 2007;31(9):13929. [CrossRef]

21. Ahmad I, Nemet D, Eliakim A, Koeppel R, Grochow D, Coussens $M$, et al. Body com-position and its components in preterm and term newborns: A cross-sectional, mul-timodal investigation. Am J Hum Biol 2010;22(1):6975. [CrossRef]

22. Garcia-Artero E, Ortega FB, Ruiz JR, Mesa JL, Delgado M, González-Gross M, et al. Lipid and metabolic profiles in adolescents are affected more by physical fitness than physical activity (AVENA study). Rev Esp Cardiol 2007;60(6):5818. [CrossRef]

23. Mikkelsson LO, Nupponen H, Kaprio J, Kautiainen H, Mikkelsson M, Kujala UM. Ado-lescent flexibility, endurance strength, and physical activity as predictors of adult tension neck, low back pain, and knee injury: a 25 year follow up study. $\mathrm{Br} \mathrm{J}$ Sports Med 2006;40(2):10713. [CrossRef]

24. Rogers M, Fay TB, Whitfield MF, Tomlinson J, Grunau RE. Aerobic capacity, strength, flexibility, and activity level in unimpaired extremely low birth weight (<or=800 g) survivors at 17 years of age compared with term-born control subjects. Pediatrics 2005;116(1):5865. [CrossRef]

25. Svien LR. Health-related fitness of seven- to 10-year-old children with histories of preterm birth. Pediatr Phys Ther 2003;15(2):7483. [CrossRef]

26. Rusch H, Irrang W. Münchner Fitnesstest. Haltung und Bewegung 1994;14(1):417. 